\title{
Prevention and Early Detection of Metabolic Syndrome in Household Community, Surabaya
}

\author{
Ema Qurnianingsih ${ }^{1}$, Lina Lukitasari ${ }^{1}$, Ira Humairah ${ }^{1}$, Citrawati Dyah KW ${ }^{1}$, Siti Khaerunnisa ${ }^{1}$, \\ Gwenny Ichsan Prabowo ${ }^{1}$, Suhartati ${ }^{2}$ \\ ${ }^{1}$ Researcher, Department of Physiology and Medical Biochemistry, Faculty of Medicine, Universitas Airlangga, \\ Surabaya, Indonesia, ${ }^{2}$ Professor, Department of Medical Biochemistry, Faculty of Medicine, Universitas Wijaya \\ Kusuma, Surabaya, Indonesia
}

\begin{abstract}
Introduction. Metabolic syndrome is a collection of factors believed to increase the risk of atherosclerosis and type 2 diabetes mellitus. The incidence of metabolic syndrome in young adults is increasing, especially in Asian countries. Therefore we need efforts to increase knowledge in society about this disease.
\end{abstract}

Aim. We conducted a socialization program on prevention and early detection of metabolic syndrome in household community to increase public knowledge about this disease.

Method. This program was conducted in August 2017 in Wonokromo District, Surabaya. The participants in the activity consisted of 32 people from household community. The activity consisted of blood sampling collection, body weight, and abdominal circumference measurement for risk factor assessment, pre-test, socialization of metabolic syndrome, and post-test.

Results. From the results of the pre and post test, we found an increase knowledge of $76.9 \%$ participants. The laboratory test results for early detection of metabolic syndrome showed $37.5 \%$ of participants had metabolic syndrome. We also found a significant positive correlation between body weight and abdominal circumference $(\mathrm{p}=0.000, \mathrm{r}=0.867)$. There was also a significant negative correlation between body weight and HDL ( $\mathrm{p}=0.004, \mathrm{r}=-0.494)$, between abdominal circumference and HDL $(\mathrm{p}<0.05, \mathrm{r}=-0.376$ ), and between TG and HDL $(\mathrm{p}<0.05, \mathrm{r}=-4.22)$.

Conclusion. Socialization and early detection of metabolic syndrome can increase knowledge, awareness, and detection of metabolic syndrome in the household community.

Keywords: prevention, early detection, metabolic syndrome, household community

\section{Introduction}

Metabolic syndrome is a collection of various metabolic disorders that are interrelated. It is a complex metabolic disorder associated with the risk of atherosclerosis and diabetes mellitus ${ }^{1,2}$. The prevalence of metabolic syndrome in the world is increasing, especially in urban areas. Sedentary lifestyle that lacks

\section{Corresponding author:}

Citrawati Dyah KW

citrawati.dyah@fk.unair.ac.id physical activity, unhealthy diet, and high-stress levels are thought to affect the incidence of this syndrome. Many studies state that the incidence of metabolic syndrome is dominated by productive age or young adults ${ }^{2,3}$. This condition is very worrying as work productivity in general is associated with the productivity of those ages.

Many consensus criteria are used to determine a person with metabolic syndrome. There are two criteria widely used for determining metabolic syndrome, the IDF and the WHO criteria. The IDF criteria are based on central abdominal circumference plus two of the four factors: TG, HDL, systolic/diastolic blood pressure, 
and fasting blood sugar levels, while the WHO criteria are based on clinical criteria of insulin resistance ${ }^{1,2,4}$. Research conducted in China showed that metabolic syndrome is more common in urban populations. Economic development and changes in diet patterns are thought to have a role in the occurrence of metabolic syndrome in urban areas compared to rural areas ${ }^{5}$.

The area of Wonokromo District, Surabaya, is located in a densely populated urban area in Surabaya. The people who live in the area are pluralistic communities with diverse cultural backgrounds and customs. However, as with urban communities in general and the demographics of areas close to various commercial centers and modern lifestyles, it is feared that the public will adopt an unhealthy lifestyle such as excessive consumption of junk food, lack of physical activity, and high-stress levels. This will cause metabolic disorders that lead to metabolic syndrome, a collection of metabolic abnormalities that can increase the risk of developing metabolic diseases such as cardiovascular disease and type 2 diabetes mellitus. Therefore, we conducted a socialization program to household community in Wonokromo District, Surabaya for prevention and early detection of metabolic syndrome.

\section{Methods}

Participantsin the activitywerehousehold community of Wonokromo District, Surabaya. In this program, the participants were measured for bodyweight, abdominal circumference, and blood pressure. The participants were also checked for laboratory examinations (fasting blood glucose, TG, and HDL cholesterol) from blood serum. Laboratory measurements were performed in Prospek laboratory, Surabaya, Indonesia, by using automated enzymatic colorimetry.

The participants were also asked to follow pre-test by filling-in close answers questions in order to find out the participants' initial knowledge regarding metabolis syndrome. The questions of the pre-test included: early detection of metabolic syndrome, ways to prevent metabolic syndrome and the risk of metabolic syndrome. After given socialization, the participants were asked to fill-in a post-test with similar questions as the pre-test to find out whether there was an increase in knowledge about metabolic syndrome.

Participants with metabolic syndrome were defined according to the International Diabetes Federation (IDF) criteria, $2006^{1}$. The diagnosis of metabolic syndrome based on IDF were central abdominal circumference of more than $80 \mathrm{~cm}$ in women and more than $90 \mathrm{~cm}$ in men plus two of four factors: TG, HDL, systolic/diastolic blood pressure and fasting blood glucose levels.

From the results obtained, statistical analysis was performed using SPSS version 23. The association between gender and laboratory parameters was analyzed by t-test, while the correlation between laboratory parameters was analyzed by Spearman.

\section{Results}

\section{Pre and post-test}

Based on the results of the pre-test and post-test, $76.9 \%$ of participants had increased of their post-test scores compared to their pre-test scores (Figure 1).

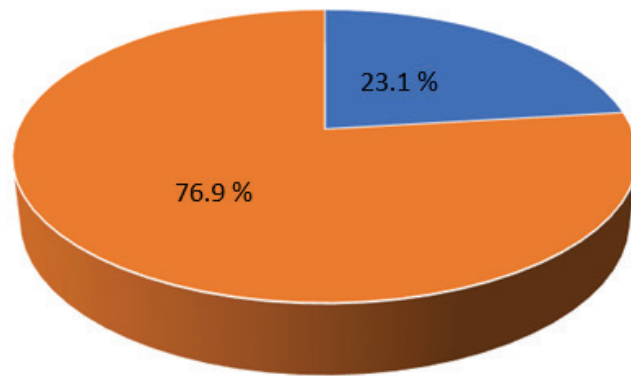

- Increase of knowledge = No increase of knowledge

Figure 1. Percentage of increased knowledge regarding metabolic syndrome of the participants before and after socialization 


\section{Laboratory examination}

The participants consisted of men and women, with a mean age of $47.39 \pm 9.39$ for women and $56 \pm 13.36$ for men. The youngest participant was 27 years old, while the oldest participant was 77 years old. The largest number of participants was in the range of 41-60 years. The gender and age characteristics of the participants can be seen in Table 1.

Table 1. Gender and age characteristics of the participants

\begin{tabular}{|c|c|c|c|c|c|}
\hline \multirow{2}{*}{ Gender } & \multicolumn{4}{|c|}{ Age (y.o) } & \multirow{2}{*}{ Total } \\
\hline & 21-40 & $41-50$ & $51-60$ & $>60$ & \\
\hline Male & 1 & 0 & 3 & 1 & 5 \\
\hline Female & 6 & 10 & 8 & 3 & 27 \\
\hline Total & 7 & 10 & 11 & 4 & 32 \\
\hline
\end{tabular}

The result of the laboratory examination for metabolic syndrome from the participants is shown in Table 2 .

Table 2. The results of laboratory examination for metabolic syndrome from the participants

\begin{tabular}{|c|c|c|}
\hline Parameters of metabolic syndromes (Mean \pm SD) & Male & Female \\
\hline Weight $(\mathrm{kg})$ & $76.2 \pm 11.15$ & $63.67 \pm 11.36$ \\
\hline Abdominal circumferences $(\mathrm{cm})$ & $99.2 \pm 11.12$ & $90.96 \pm 10.87$ \\
\hline Systolic blood pressure $(\mathrm{mmHg})$ & $134 \pm 21.91$ & $91.11 \pm 11.39$ \\
\hline Diastolic blood pressure $(\mathrm{mmHg})$ & $92 \pm 4.47$ & $101.96 \pm 57.84$ \\
\hline TG $(\mathrm{mg} / \mathrm{dL})$ & $185 \pm 101.08$ & $53.33 \pm 8.7$ \\
\hline HDL $(\mathrm{mg} / \mathrm{dL})$ & $45.8 \pm 8.2$ & $89.59 \pm 55.49$ \\
\hline Fasting blood glucose $(\mathrm{mg} / \mathrm{dL})$ & $77.6 \pm 12.28$ & \\
\hline
\end{tabular}

The results showed that female participants had lower bodyweight, abdominal circumference, systolic blood pressure, diastolic blood pressure, and TG levels compared to males. The female also had higher levels of HDL and fasting blood glucose than male participants.
From a total of 32 participants, 12 participants $(37.5 \%)$ were detected with metabolic syndrome (Figure 2). The most common type of metabolic syndrome was abdominal circumference exceeded normal limits $(100 \%)$. 


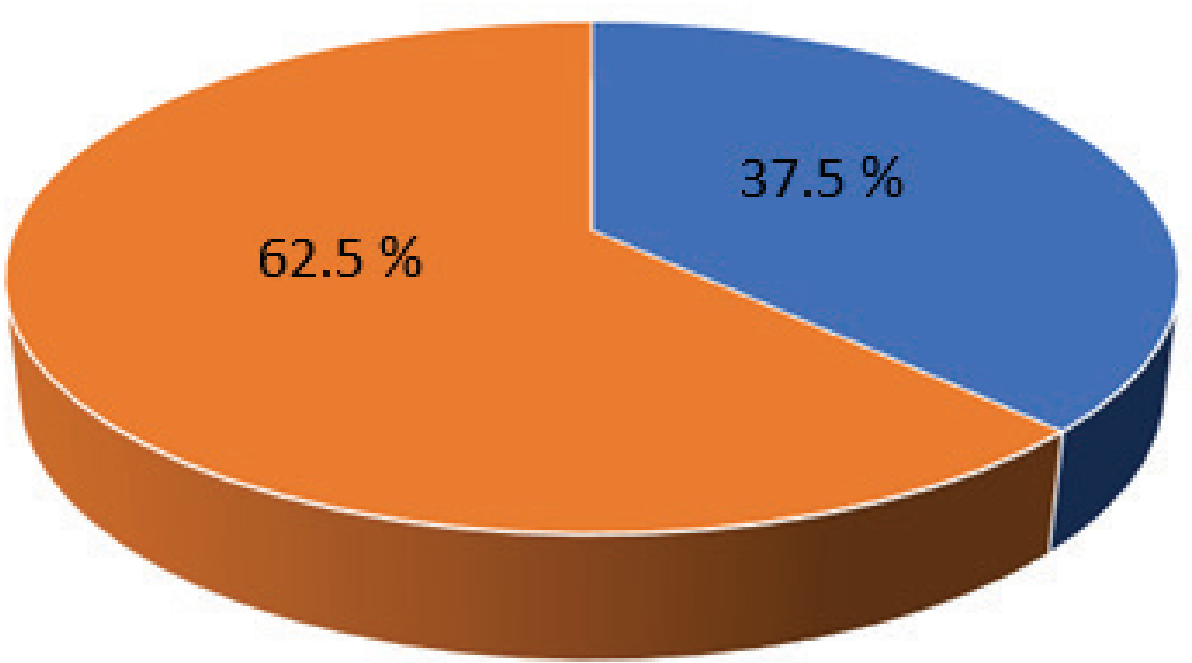

\section{- Participant with metabolic syndrome - Participant without metabolic syndrome}

Figure 2. Percentage of participants with metabolic syndrome

Of the 12 participants who detected metabolic syndrome, most of them (11 participants) were of productive age (25-65 years) as shown in Figure 3.

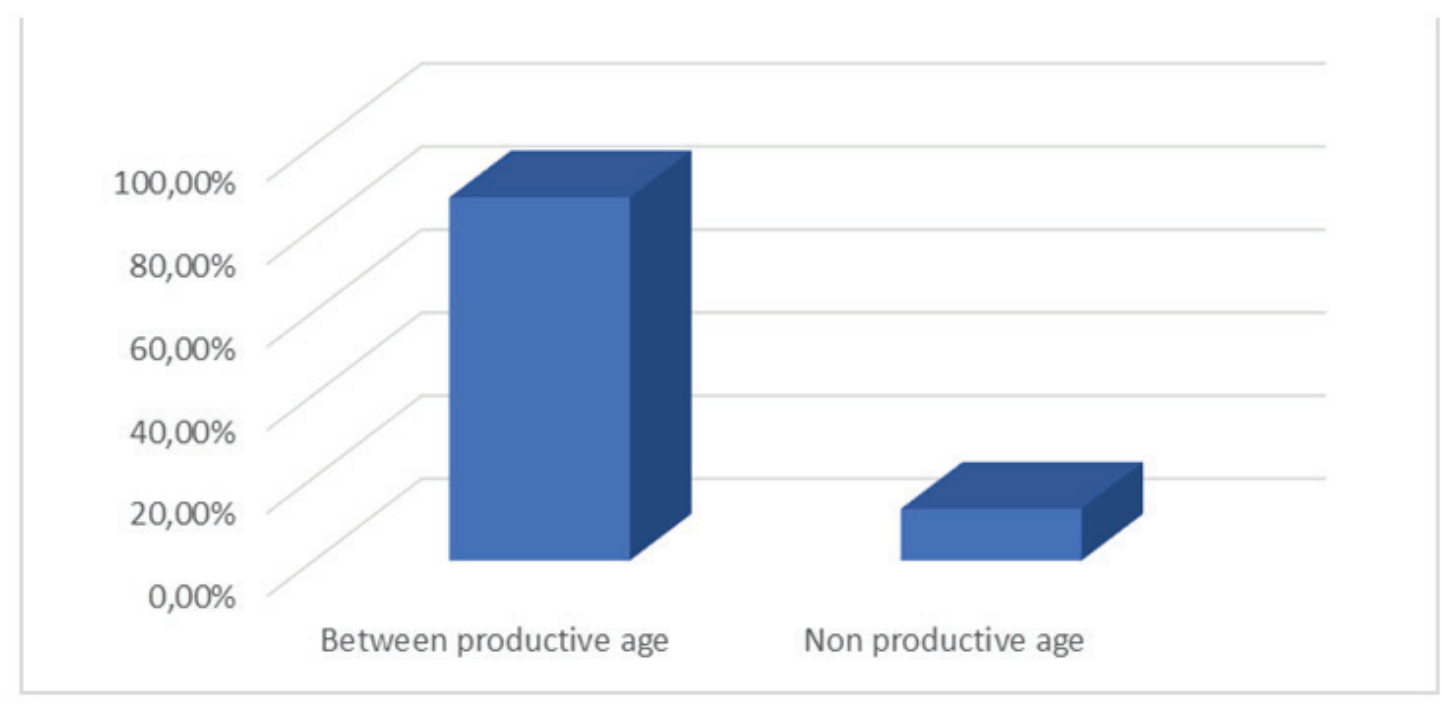

Figure 3. Comparison of the percentage of participants with metabolic syndrome between productive age and non-productive age

In this program, female participants with metabolic syndrome were more frequent than male (Figure 4), however, this could not be generalized as the number of female participants was more than male. 


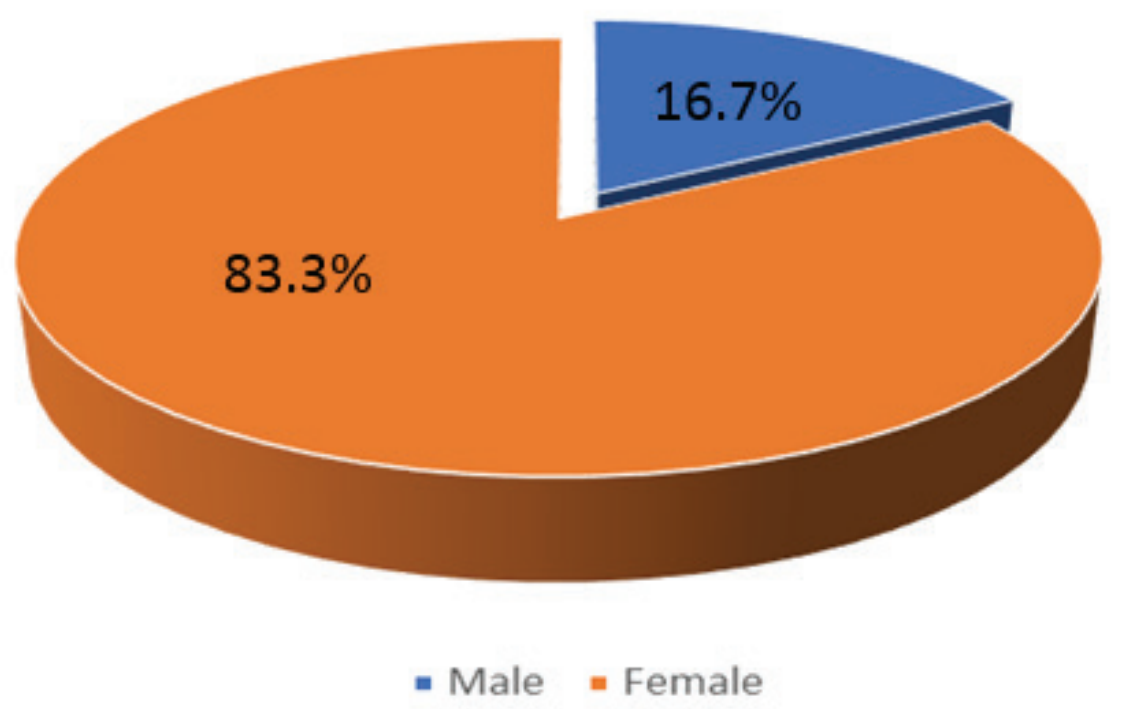

Figure 4. Percentage of male and female participants with metabolic syndrome

From the participants, Pearson correlation test showed a significant positive correlation between body weight and abdominal circumference $(\mathrm{p}=0.000, \mathrm{r}=$ $0.867)$. In addition, there was also a significant negative correlation between body weight and $\operatorname{HDL}(\mathrm{p}=0.004, \mathrm{r}$ $=-0.494$ ), between abdominal circumference and HDL $(\mathrm{p}<0.05, \mathrm{r}=-0.376)$, and between TG and HDL ( $\mathrm{p}$ $<0.05, \mathrm{r}=-4.22)$.

\section{Discussions}

Metabolic syndrome is a set of markers of cardiometabolic risk whose incidence is increasing worldwide. These conditions include insulin resistance, hypertension, central obesity, glucose intolerance, and dyslipidemia ${ }^{6}$. In Indonesia itself, based on research conducted by Herningtyas \& Ng (2019), the overall prevalence of metabolic syndrome is relatively high $(21.66 \%)$, with one of which the highest distribution is in East Java. The study also shows that the prevalence in urban communities is higher than in rural areas ${ }^{7}$. In this program, we found a high incidence of metabolic syndrome $(37.5 \%)$, which is not much different from that study.

Most of the participants with metabolic syndrome in this program were of productive age (young adults). It is said that the prevalence of metabolic syndrome in young adults has increased in the last 15 years ${ }^{8}$. This can be caused by Westernized diet, sedentary lifestyle, excessive alcohol intake, and smoking at productive age ${ }^{9}$. However, early detection of metabolic syndrome in young adults can provide more effective prevention because of cost-saving and reducing disability-adjusted life years ${ }^{10}$.

Prevention and early detection of metabolic syndrome is an important effort in reducing the incidence of this disease. Increasing awareness and knowledge of metabolic syndrome through specific health education can improve the quality of public health, considering that public knowledge of this disease is still low ${ }^{11}$. In this program, there was a $76.9 \%$ increase in people's knowledge regarding metabolic syndrome, which was assessed from the results of the pre-test and post-test. This proves that socialization about metabolic syndrome can provide a comprehensive understanding of public knowledge regarding this disease.

In this program, we found a significant positive correlation between body weight and abdominal circumference, significant inverse correlations between body weight and HDL, between abdominal circumference and HDL, and between TG and HDL. This was in line with previous studies showing 
significant positive correlation between body weight and abdominal circumference ${ }^{12}$, significant negative correlation between body weight and HDL ${ }^{13}$, between abdominal circumference and HDL ${ }^{14}$, and between TG and $\mathrm{HDL}^{15}$.

This program had contribution for the community to reduce the incidence of metabolic syndrome in Indonesia, especially in urban household community. Early detection of metabolic syndrome from the smallest community unit also helps better management of metabolic syndrome to prevent further cardiometabolic complications.

\section{Conclusions}

Socialization program was effective to increase knowledge about metabolic syndrome in the household community. On laboratory examination, $37.5 \%$ of the participants were detected with metabolic syndrome, in which most of them were in productive age. Additional support from the community is needed, and similar programs should be carried out in other places to reduce the incidence of metabolic syndrome and its related complications in Indonesia.

Patient's informed consent: Patient's informed consent has been obtained.

\section{Conflict of Interest: Nil}

Funding: Our gratitude goes to the Dean of the Faculty of Medicine, Universitas Airlangga, who had given permission and funds for the implementation of the program with the Decree Number : 133 / UN3.1.1/ $\mathrm{KD} / 2017$.

\section{References}

1. IDF. International diabetes federation, the IDF consensus worldwide definition of the metabolic syndrome. Int Diabetes Fed. 2006;

2. Kassi E, Pervanidou P, Kaltsas G, Chrousos G. Metabolic syndrome: Definitions and controversies. BMC Med. 2011;

3. Ford ES, Giles WH, Dietz WH. Prevalence of the metabolic syndrome among US adults: Findings from the Third National Health and Nutrition Examination Survey. J Am Med Assoc. 2002;

4. World Health Organization (WHO). Definition ,
Diagnosis and Classification of Diabetes Mellitus and its Complications Part 1: Diagnosis and Classification of. World Health. 1999;

5. Xi B, He D, Hu Y, Zhou D. Prevalence of metabolic syndrome and its influencing factors among the Chinese adults: The China Health and Nutrition Survey in 2009. Prev Med (Baltim). 2013;

6. Bruce $\mathrm{KD}$, Byrne $\mathrm{CD}$. The metabolic syndrome: Common origins of a multifactorial disorder. Postgrad Med J. 2009;85(1009):614-21.

7. Herningtyas EH, Ng TS. Prevalence and distribution of metabolic syndrome and its components among provinces and ethnic groups in Indonesia. BMC Public Health. 2019;19(1):1-12.

8. Mattsson N, Rönnemaa T, Juonala M, Viikari JSA, Raitakari OT. The prevalence of the metabolic syndrome in young adults. The Cardiovascular Risk in Young Finns Study. J Intern Med. 2007;261(2):159-69.

9. Sekgala MD, Monyeki KD, Mogale A, Mchiza ZJ, Parker W, Choma SR, et al. The risk of metabolic syndrome as a result of lifestyle among Ellisras rural young adults. J Hum Hypertens [Internet]. 2018;32(8-9):572-84. Available from: http:// dx.doi.org/10.1038/s41371-018-0076-8

10. Šoštarič A, Jenko B, Kozjek NR, Ovijač D, Šuput D, Milisav I, et al. Detection of metabolic syndrome burden in healthy young adults may enable timely introduction of disease prevention. Arch Med Sci. 2019;15(5):1184-94.

11. Wang Q, Chair SY, Wong EML, Taylor-Piliae RE, Qiu XCH, Li XM. Metabolic syndrome knowledge among adults with cardiometabolic risk factors: A cross-sectional study. Int J Environ Res Public Health. 2019;16(1):1-10.

12. Miyatake N, Matsumoto S, Miyachi M, Fujii M, Numata T. Relationship between changes in body weight and waist circumference in Japanese. Environ Health Prev Med. 2007;12(5):220-3.

13. Park KH, Yadav D, Kim SJ, Kim JR, Cho KH. Slim body weight is highly associated with enhanced lipoprotein functionality, higher HDL-C, and large HDL particle size in young women. Front Endocrinol (Lausanne). 2018;9(JUL):1-12.

14. Chehrei A, Sadrnia S, Keshteli AH, Daneshmand MA, Rezaei J. Correlation of dyslipidemia with waist to height ratio, waist circumference, and body mass index in Iranian adults. Asia Pac J Clin Nutr. 
2007;16(2):248-53.

15. Wakabayashi I. Inverse association between triglycerides-to-HDL-cholesterol ratio and alcohol drinking in middle-aged Japanese men. J Stud Alcohol Drugs. 2012;73(6):998-1004. 